\title{
Harmonized European Standards for Proof of Competence of Cranes
}

\author{
Stefan Vöth ${ }^{1, *}$, Guido Schneider ${ }^{1}$, and Maxim Tyulenev ${ }^{2}$ \\ ${ }^{1}$ Technische Hochschule Georg Agricola (THGA), Bochum, Germany \\ ${ }^{2}$ T.F. Gorbachev Kuzbass State Technical University, 650000, 28 Vesennyaya St., Kemerovo, Russia
}

\begin{abstract}
With EN 13001-1 ff. a harmonized set of standards for safety of cranes was and is established. Due to harmonization the use of the standards leads to the assumption of conformity with the safety requirements of the machinery directive. A major argument for the application of the standards. The standards comprise new concepts of proof of competence in comparison to previous standards. Keywords of these new concepts are "Classification", "Limit state method", "Mass Distribution Class" and "Partial safety factors". The article gives an overview to EN 13001-1, EN 13001-2 and EN 13001-3-1. This is the set of standards for proof of the structural parts of a crane. The main aspects of the standards are shown and discussed with regard to their impact on calculation.
\end{abstract}

\section{General}

The European standards for proof of competence of cranes EN 13001-1 ff. is a set of C-type standards acc. to EN ISO 12100, which serves the assumption of conformity with the EC machinery directive.

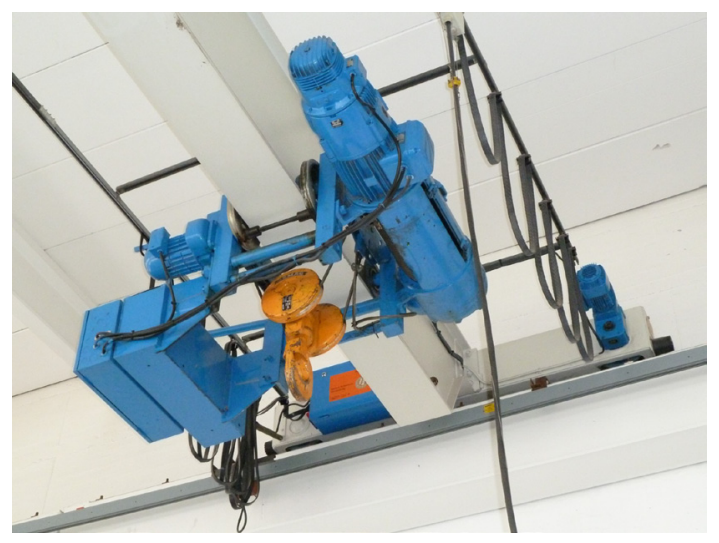

Fig. 1. Bridge crane at THGA.

\footnotetext{
* Corresponding author: stefan.voeth@thga.de
} 
The set of standards consists of part EN 13001-1 „General principles and requirements“, part EN 13001-2 „Load actions“ and several (drafted) parts 3 which give limit states for different mechanical components. Part EN 13001-3-1 „Limit states and proof of competence of steel structure“. Part EN 13001-3-2 „Limit states and proof of competence of wire ropes in reeving systems“. Part EN 13001-3-3 „Limit states and proof of competence of wheel/rail contacts“. Part EN 13001-3-4 „Limit states and proof of competence of machinery - Bearings“. Part EN 13001-3-5 „Limit states and proof of competence of forged hooks“. Part EN 13001-3-6 „Limit states and proof of competence of machinery - Hydraulic cylinders“. Following text gives explanations on EN 13001-1, EN 13001-2 and EN 13001-3-1.

\section{General Principles and Requirements}

EN 13001-1 „General principles and requirements“ covers the concept for proof of competence and classification parameters.

The standard covers the reduction or elimination of certain hazards: Mechanical strength (yield strength, fracture strength, fatigue strength), rigid body instability, elastic stability (buckling, bulging), deformation and heating.

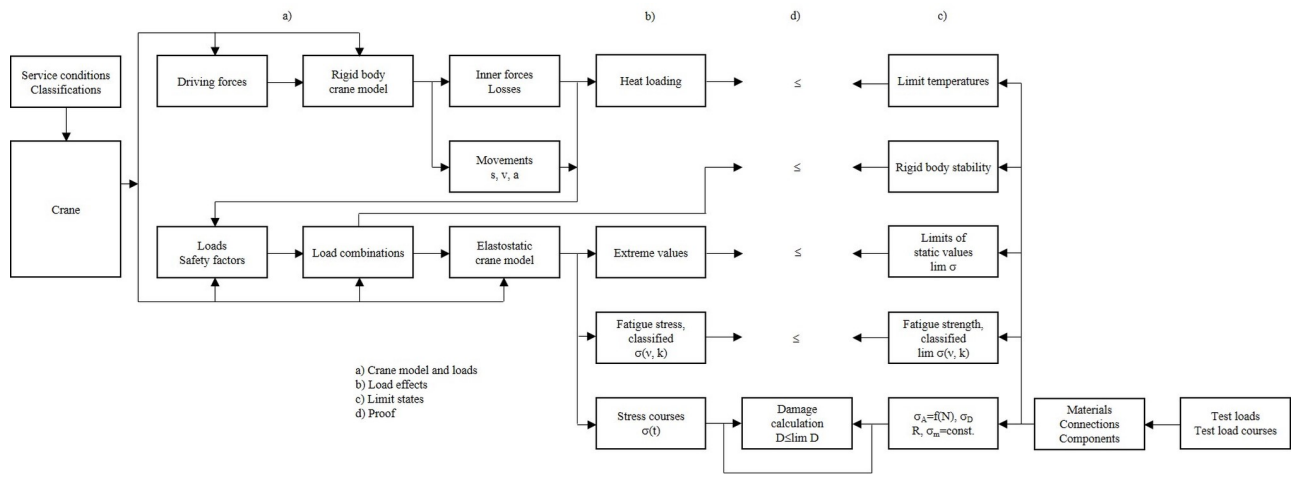

Fig. 2. Proofs to be executed.

For the proof the limit state method and the permissible stress method may be applied. The limit state method applies partial safety factors onto the different loads, which gives the opportunity of different evaluation of different loads. This may be of special importance in cases of non-linear effects or of poor quality of load evalutation. The permissible stress method applies a global safety factor onto the sum of resulting stresses. This „classical“ method leads to the same results as the limit state method in case of linear systems, as long as the total safety factors are the same.

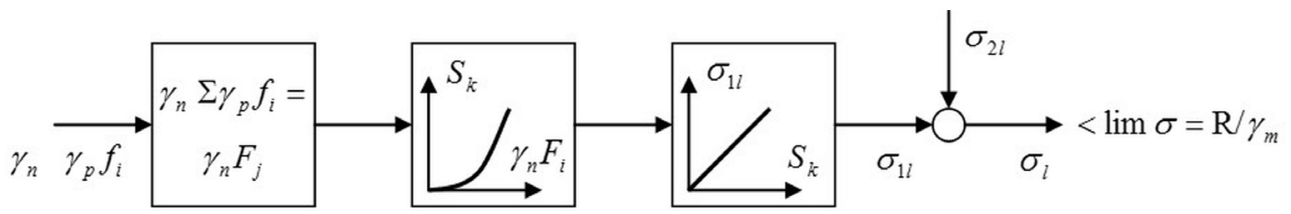

Fig. 3. Concept of limit state method.

For classification of cranes a set of classification parameters is introduced. The parameters indicate the intensity of usage of the crane with regard to different aspects. The classification of the total number of load cycles, the medium driving distances, the relative 
frequency of loads and the mean number of accelerations per movement. Furthermore, the stress course parameter classifies the intensity of fatigue loading of a certain crane detail.

\section{Load Actions}

EN 13001-2 „Load actions“ covers the various loads on cranes.

Loads are grouped in regular loads, non-regular laods and exceptional loads.

Regular loads occur regularly during usual operation: Acceleration of masses of crane due to gravitation and lifting, gravitation and inertia acting onto vertically onto the load, loads out of driving across unevenessses, acceleration of crane drives and loads out of forced deformations.

Non-regular loads occur seldom during usual operation: Loads out of wind in service, snow and ice loads, loads out of heat and loads out of skewing.

Exceptional loads occur seldom during usual operation: Loads out of raising a load from ground under exceptional conditions, loads out of wind out of service, test loads, loads out of buffer impact, loads out of tilting forces, loads out of emergency stopp, loads out of dynamic switch-off due to load limit switch, loads out of dynamic switch-off due to torque limit switch, loads out of unintended loss of the load, loads out of drive or component failure, loads out of external excitation of crane structure and loads out of assembly and disassembly.

The calculation bases on a rigid body model. Dynamic effects are considered by dynamic factors for own masses, for the load raised from the ground, for partial loads dropped off, for driving over unevenesses, for acceleration of drives, for test loads, for buffer collision and for unintended loss of load.

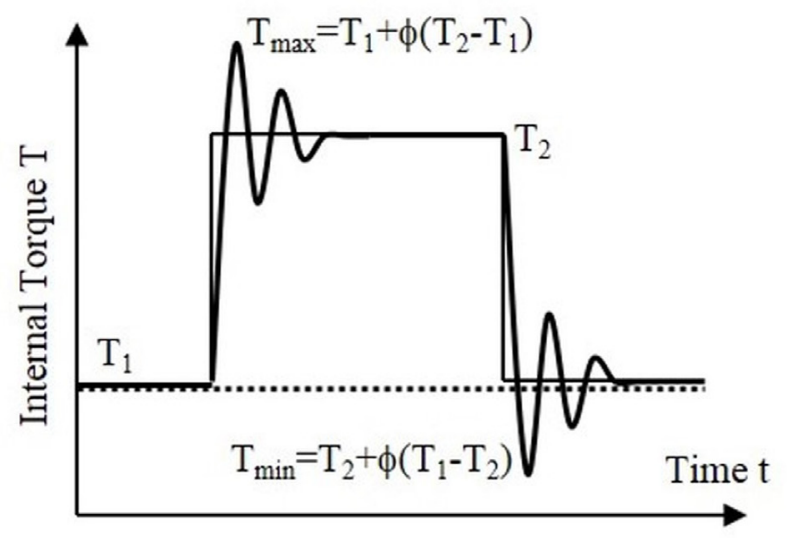

Fig. 4. General definition of dynamic factors.

Rules for the calculation of loads out of wind in service, out of wind out of service, skewing, action of load limit switch, action of torque limit switch, weight of ascents are given.

The loads are combined in so called load combinations. Load combinations A combine regular loads. Load combinations B combine regular loads and non-regular loads. Load combinations $\mathrm{C}$ combine regular loads, non-regular loads and exceptional loads. For load combinations A the yield strength and the fatigue strength have to be proofed. For load combinations A and B the yield strength has to be proofed. 


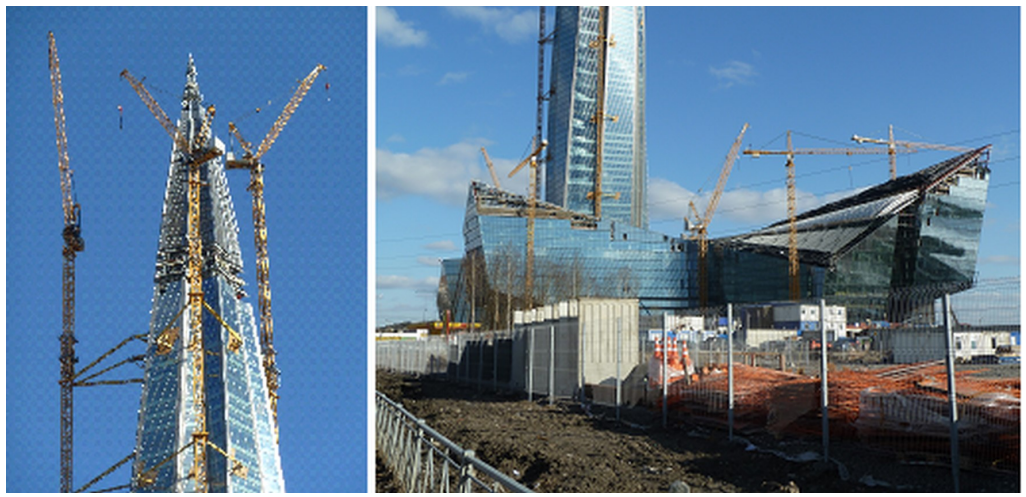

Fig. 5. Tower cranes at Lachta Centre, St. Petersburg.

The safety level is adjusted by safety factors. Using the limit states concept all loads are evaluated by certain partial safety factors. The partial safety factor for the cranes masses and for forced deformations depend on unfavourable or favourable character. The safety level given by the partial safety factor can be increased by a risk coefficient in case of high risk applications. The limit states are reduced by a general resistance factor and a special resistance factor for the design detail considered. For the proof of fatigue strength the partial safety factors are set to $\gamma \mathrm{p}=1,0$.

For the proof of stability special load combinations and partial safety factors are defined.

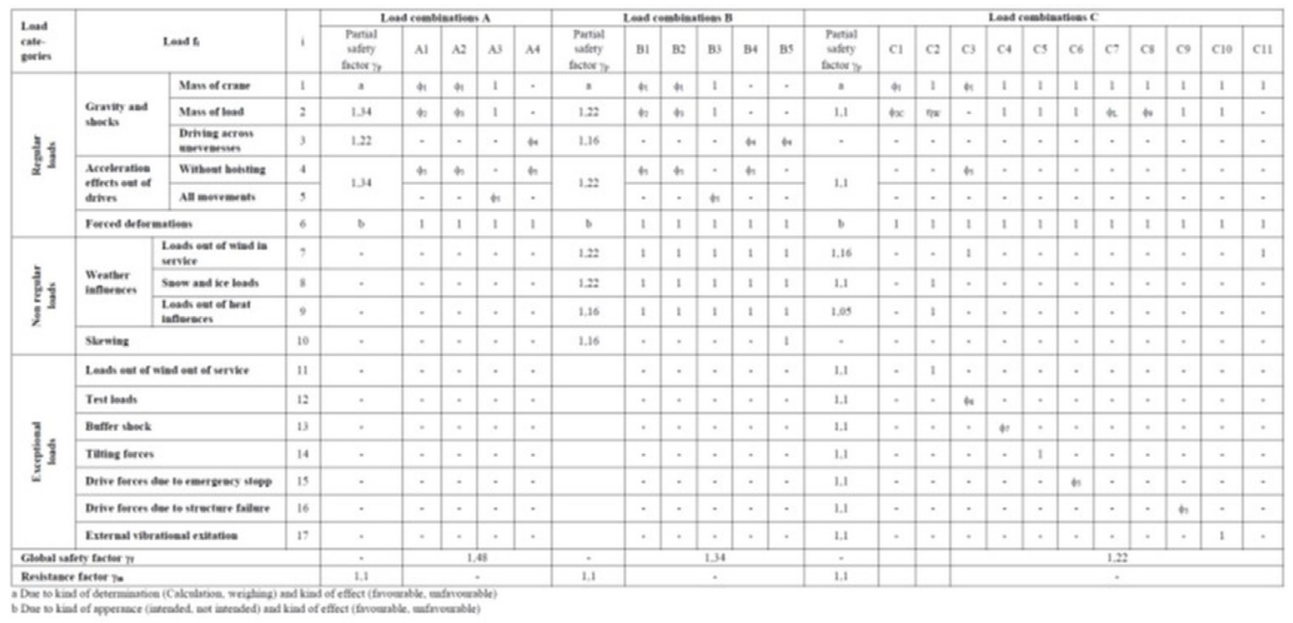

Fig. 6. Loads, Load combinations, dynamic factors, partial safety factors, global safety factors.

\section{Limit States and Proof of Competence of Steel Structures}

EN 13001-3-1 „Limit states and proof of competence of steel structure“ covers the rules for proof of competence and limit states for different design details.

Details covered for the proof of static strength are material of parts, screwed joints, bolted joints and welded joints. Details covered for the proof of fatigue strength are material of parts, non-welded connections, welded parts and hollow profiles.

For statical proof especially following details are considered: Parts: Proof of singular stresses and composed stress. Screwed joints: Proof of screw shear force, part support 
force, part stress in residual cross section, sliding force, maximum stress, gaping, composed stress. Bolted joints: Shear force, support force of parts, support force of bolt, shear force of parts, tensional force of parts. Welded joints: Proof of singular stresses and composed stress.

The limit states of dynamical stresses are described by curves according to Wöhler. The curves are defined by the negative inverse slope $\mathrm{m}$ and the characteristic stress span $\Delta \sigma_{\mathrm{c}}$. For the negative inverse slope values of $\mathrm{m}=3$ and $\mathrm{m}=5$ are set. The characteristic stress span $\Delta \sigma_{\mathrm{c}}$ is the stress span at $\mathrm{N}_{\mathrm{ref}}=2 \cdot 10^{6}$.

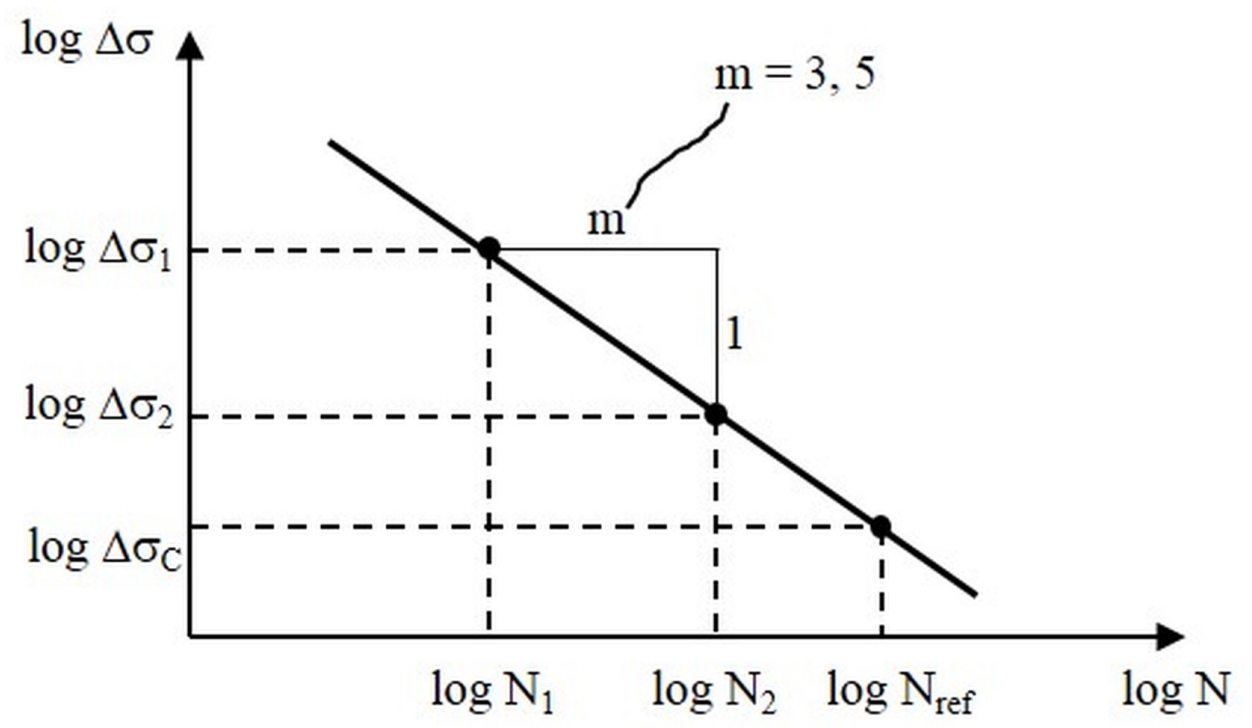

Fig. 7. Definition of limits states for dynamic stresses.

\section{References}

1. D. Wehner, Neue Europanorm für Krane, 5, 66 (2015)

2. D. Wehner, Neue Europanorm für Krane, 1:2, 70 (2015)

3. S. Schneidler, M. Kleeberger, Kranfachtagung, 3, 24 (2012)

4. W. Warkenthin, Betrachtungen zur Windlastannahme nach, 47, 10 (2007)

5. J. Gentzsch, Kranfachtagung, 3, 26 (2006)

6. M. Golder, Kranfachtagung, 5, (2004)

7. G. Wagner, J. Scholten, H. Haensel, Kranfachtagung, 5, 22 (2003)

8. R. Obretinow, G. Wagner, Stahlbau, 4, 218 (2000)

9. S. Vöth, Restlebensdauerabschätzung für Krananlagen, 1:2, 65 (1996)

10. R. Obretinow, CEN-Krannorm, 10, 431 (1996) 